Jelena V. Badovinac

Univerzitet u Novom Sadu

Filozofski fakultet

Studentkinja doktorskih studija

jelenabadovinac@gmail.com
UDK: 821.131.1.09-31

doi: 10.19090/zjik.2021.155-167 originalni naučni rad

\title{
RECEPCIJA ROMANA MOJA GENIJALNA PRIJATELJICA ELENE FERANTE KROZ PRIZMU ODNOSA IZMEĐU GLAVNE JUNAKINJE I NJENE MAJKE
}

SAŽETAK: U radu izdvajamo najvažnije aspekte koji utiču na recepciju romana Moja genijalna prijateljica Elene Ferante na teritoriji naše zemlje. Takođe, detaljno ispitujemo kulturološki kontekst pri transferu romana na srpski jezik i određujemo funkciju koju njegov prevod ima u ciljnoj kulturi. Imajući na umu njihovu relevantnost u ocenjivanju i recepciji nekog književnog dela, pravimo osvrt na stavove koje, u pogledu prvog romana napuljske tetralogije, iznosi domaća književna kritika. S obzirom na to da je cilj rada otkrivanje uloge koju protagonistkinja i njena majka imaju u recepciji, posebnu pažnju usmeravamo na kompleksni odnos koji se između njih razvija. Kako bismo odredili uticaj tog odnosa na recepciju ovog dela, analiziramo lik Elene, odlučne na putu ka emancipaciji, i lik majke, koja se ne opire stegama patrijarhata, već ga prihvata kao nužnost. Stavljajući fokus na dinamičan odnos obeležen antagonizmom između dve generacije ženâ, nastojimo da ukažemo na to da ga čitalačka publika neretko doživljava bliskim ličnom iskustvu.

Ključne reči: Elena Ferante, Moja genijalna prijateljica, recepcija, čitalačka publika, odnos majke i ćerke, patrijarhalna kultura, emancipacija

\section{UVODNA RAZMATRANJA O ROMANU}

Polazeći od činjenice da je ,žensko pitanje”, odnosno borba za rodnu ravnopravnost fenomen koji egzistira i danas, nezavisno od stepena razvoja nekog društva, smatramo da književna dela koja tretiraju položaj žene, među koja se ubraja i roman Moja genijalna prijateljica (L'amica geniale) Elene Ferante ${ }^{1}$, aktivno podstiču interesovanje šire javnosti za razmatranje ovog pitanja. Prvi

\footnotetext{
${ }^{1}$ Italijanska književnica Elena Ferante ovaj prvi, od ukupno četiri dela napuljske sage, objavljuje 2011. godine. Nakon toga pojavljuju se i njegovi nastavci: Storia del nuovo cognome (Priča o drugom prezimenu) 2012, Storia di chi fugge e di chi resta (Priča o onima koji odlaze i onima koji ostaju) 2013. i Storia della bambina perduta (Priča o izgubljenoj devojčici) 2014.
} 
roman napuljske tetralogije, koji će biti predmet naše analize, podeljen je u tri poglavlja: Prolog - Brisanje tragova, Detinjstvo - Priča o don Akileu i Mladost Priča o cipelama. Autorka smešta radnju romana u siromašno predgrađe Napulja nakon Drugog svetskog rata. Mesto, vreme, kao i životni uslovi tog perioda u velikoj meri utiču na razumevanje okolnosti u kojima žive junaci ove priče. Ekonomska održivost celog naselja zavisi od dve uticajne porodice koje su bogatstvo stekle zahvaljujući prevashodno kriminalnim aktivnostima. Takav način poslovanja, u koji su direktno ili indirektno uvučeni, nemo prihvataju gotovo svi članovi zajednice, dok otpor pruža tek poneki pojedinac koji ubrzo biva ućutkan. Uprkos životu na rubu egzistencije i konstantnom strahu, stanovnici ovog malog naselja ostaju nemoćni pred silom jačeg, te se prepuštaju milosti zelenaških porodica Solara i Karači. Iz takvog ambijenta potiče protagonistkinja Elena Greko, koja, nakon iznenadnog nestanka najbolje prijateljice Lile u poznim godinama, odlučuje da sačuva od zaborava svoja sećanja o događajima koji su obeležili period zajedničkog odrastanja.

Preuzimajući ulogu naratorke u priči koju Ferara opisuje kao ,priču o preživljavanju, a ne o žrtvi, u kojoj se razvijaju kreativni oblici otpora patrijarhalnim hijerarhijama moći"2 (Ferrara 2020: 560), Elena potresno oslikava sudbine ljudi koji žive u svom zatvorenom svetu. Na početku romana autorka kreira identitetske uloge svih likova navodeći precizan spisak na osnovu kojeg se odmah uočava da je položaj članova porodica određen očevim zanimanjem. Tako nam Ferante, pre nego što nas uvede u radnju romana, nedvosmisleno daje do znanja da su njeni likovi predstavnici patrijarhalne kulture. U aktuelnim društveno-ekonomskim prilikama u Napulju polovinom XX veka, naratorka kao centralnu temu izdvaja svoje prijateljstvo sa Rafaelom Čerulo - Linom ili Lilom, koje je protkano konstantnim nadmetanjem, ali i neverovatnom bliskošću.

Postoje tvrdnje da je reč o romanu koji u sebi obuhvata više žanrova, od noara do istorijskog romana (Piazza 2020: 54) ili, drugim rečima, da „on pripada žanru društvenog romana isto koliko i psihološkom ili romanu o razvoju ličnosti i romanu o razvoju umetnice" (Šljukić 2017: 66). S obzirom na to da ćemo u analizi recepcije romana poseban fokus staviti na Elenino odrastanje i pokušaj emancipacije u osetljivom adolescentskom dobu, u ovom radu ćemo ga posmatrati kao bildungsroman. Bildungsroman predstavlja nemački žanr romana koji govori o procesu stvaranja karaktera (Sirković 2011, para. 1). Kada je reč o ženskom

\footnotetext{
$2[\ldots]$ it is a tale of "survival, not of victimhood" in which "creative forms of resistance" to patriarchal hierarchies of power are developed. (Svi prevodi citiranih engleskih i italijanskih izvora u ovom radu su autorkini.)
} 
bildungsromanu, on dobija najviše na značaju u književnoj kritici sedamdesetih godina XX veka usled uticaja feminističkog pokreta. Pozivajući se na Elen Morgan i njeno razmatranje ovog žanra, Sirković ističe da bildungsroman „opisuje Ženski samorazvoj prema sadašnjem i budućem postojanju” (ibid. para. 29). Ženski bildungsroman predstavlja deo tzv. ženske proze, koja je mahom namenjena ženskoj čitalačkoj publici s obzirom na to da uglavnom obrađuje tradicionalne i savremene aspekte života ženâ. Kao okosnica romana Moja genijalna prijateljica izdvajaju se upravo one teme koje zauzimaju centralnu poziciju u okviru ženske proze - položaj žene u društvu, muška dominacija, rodni odnosi, kao i otkrivanje ženskog identiteta kroz proces introspekcije.

\section{OSVRT NA RECEPCIJU PRVOG ROMANA IZ NAPULJSKE SAGE}

Kada je reč o recepciji nekog književnog dela, pa tako i ovog romana, potrebno je sagledati širi kontekst ciljne kulture, te razne političke, ekonomske i šire kulturološke aspekte (Veselinović 2018: 7). Imajući na umu ove elemente, a pozivajući se na gledišta koja iznosi Šapiro u radu „Prevodilačke norme i društvena ograničenja", Veselinović objašnjava da u procesu recepcije veliku ulogu mogu imati međusobni odnosi između dve zemlje, ekonomski faktori, te politički sistemi koji u njima vladaju (ibid. 12), a koji vrlo često zauzimaju različite pozicije u izvornoj i ciljnoj kulturi. Stoga, u širem smislu gledano, pozitivna kulturološka percepcija zemlje u koju je smeštena radnja romana, umnogome doprinosi afirmativnom stavu koji se prema njemu zapaža na prostoru Srbije.

Govoreći o recepciji italijanske književnosti izvan granica Italije, Skafai navodi da je presudan odnos između kodeksa i referenta, te pod kodeksom podrazumeva jezik, odnosno njegovu prevodljivost na jezik druge kulture, dok referentom smatra istorijski ili društveni kontekst (Scaffai 2018: 41). Prevođenje književnog dela predstavlja izuzetno složen proces, te je pri prevodu neophodno ostvariti „smisaoni, sadržajni i žanrovsko-stilski ekvivalent originala, u kome bi forma i sadržina u jeziku prevoda činila isto dijalektičko jedinstvo koje predstavlja original" (Stojnić 1980: 9-10). Takođe, prevođenje je i neka vrsta književnog aktivizma koji uključuje prevodioce u kulturne rasprave kroz koje se otvaraju novi putevi kulturne komunikacije (Simon 2005: IX). Pri transponovanju na jezik ciljne kulture očigledno je da se prevodilac ovog romana suočio sa autorkinim zahtevnim pristupom koji se uočava kroz složene opise, čak i kada je reč o melodramatičnim temama. Svakom aspektu priče Ferante daje na značaju, te je pri prevođenju bilo neophodno svaki detalj uspešno integrisati u prevod. 
Smatramo da je i društveno-ekonomski kontekst, u koji autorka smešta radnju romana, značajan za recepciju romana u Srbiji, s obzirom na to da, pored razlika, postoje izvesne sličnosti između italijanskog i srpskog socijalnog ambijenta karakterističnog za period pedesetih godina prošlog veka. To vreme u Jugoslaviji Holst opisuje kao doba kada su se muškarci vratili iz rata, a žene kućama. „Uloga žene je da bude podsticajna supruga, majka i domaćica. Politika i proizvodnja su bili zadaci muškaraca" (Holst u: Milinkov 2014: 174). Slične okolnosti na globalnom nivou dovode do potrebe za emancipacijom ženâ, te pojave ženske proze u evropskoj i anglo-američkoj književnosti zahvaljujući kojoj se čitalačka publika proširuje i na taj način aktivno uključuje u aktuelne teme.

Kako će kritika i čitalačka publika prihvatiti neko književno delo u ciljnoj kulturi, zavisi i od procesa ,transfera književnog teksta iz jedne sredine u drugu, sa jednog jezika na drugi" (Veselinović 2018: 9), dakle, od društvene pozicije teksta, ali i od učesnika u tom procesu (ibid.). Na taj proces nesumnjivo utiče i status koje to delo ima u izvornoj kulturi, odnosno od njegove recepcije u drugim kulturama. Prvi roman napuljske tetralogije zajedno sa svojim nastavcima postiže najveći uspeh u SAD-u i Velikoj Britaniji ${ }^{3}$, dok se njegova recepcija u Italiji smatra ambivalentnom (Schwartz 2020: 123) ${ }^{4}$.

Ferara zapaža da u ovoj paraboli o emancipaciji upravo ženski likovi, marginalizovani i ograničeni zbog pola, niže klase i ekonomskog statusa, privlače pažnju velikog broja čitalaca širom sveta (Ferrara 2020: 560). Pored toga, u recepciji važnu ulogu igra i činjenica da je u romanu opisana prva generacija žena koja je rođena nakon dobijanja prava glasa u Italiji. Stoga se može pretpostaviti da se kod čitateljki i čitalaca znatiželja budi delimično i zbog otkrivanja početaka višedecenijske borbe za ekonomsku i društvenu ravnopravnost koje žene započinju.

Veliki deo čitalačke publike u Srbiji, koji se rado susreće sa domaćim delima i opusima koji tretiraju različite aspekte žene, svesrdno prihvata ovaj roman. Društvena klima koja je poslednjih decenija počela da prepoznaje i

${ }^{3} \mathrm{U}$ renomiranim britanskim i američkim listovima, kao što su The Indipendent, The Gardian i The New Yorker, izlaze tekstovi koji s oduševljenjem pišu o svim delovima napuljske tetralogije. The Gardian objavljuje tekst u kome se navodi da autorkino pisanje obiluje takvom intimnošću da se čini kao da kroz njene likove čitamo sopstvene misli (O’Rourke 2014, para 3).

${ }^{4}$ Prvobitne reakcije italijanske književne kritike na roman Moja genijalna prijateljica prevashodno su bile negativne, budući da ga neretko naziva feljtonom, odnosno romanom lišenim stila (Ricci 2015, para 3/5), a tek nakon internacionalnog uspeha autorkino delo se poredi sa najznačajnijom svetskom literaturom (Schwartz 2020: 135). 
podstiče žensku borbu za ravnopravnost, sve češće pokazuje radoznalost prema ženskoj reči. Međutim, treba imati na umu da, usled heterogenosti čitateljske strukture kojoj doprinosi izdavač ${ }^{5}$, može doći do pojednostavljenog razumevanja i prepoznavanja feminističkog angažmana u romanu. U javnom prostoru autorka se opisuje kao plodna i umetnički ostvarena književnica „koja piše pitko i zavodljivo" (Bazdulj 2015, para. 6). Smatrao se feminističkim romanom ili ne, ovaj roman odjeknuo je u feminističkim krugovima i zainteresovao i feministkinje budući da se bavi međusobnim odnosima ženâ, socijalnim položajem žene, kao i društvenom ulogom koja ženi biva dodeljena. Kritika vrednuje ovaj roman ističući sposobnost autorke da aktivno uključi čitateljke i čitaoce, odnosno da „ne štedi ni likove, ni nas" (Bobičić u: Savković 2019, para. 7). Iako povremeno opisuje svet na vrlo okrutan način, autorka iz njega ne isključuje ljubav i međusobno prihvatanje (ibid.). Takođe, uz dinamiku pripovedanja kroz građenje napetosti, pa sve do kontrole samog teksta, Ferante u samim čitaocima pobuđuje neku vrstu osnaživanja vešto iznoseći potisnute emocije svojih junaka (Bobičić u: Krtinić 2020, para. 5). Za interesovanje kod publike i kritike umnogome je zaslužna „naracija zasnovana na neprekidnom dovođenju čitateljki i čitalaca u zabludu, a zatim na razaranju tih iluzija" (Lalatović 2017: 45). Najočigledniji primer ovakve naracije jeste nedoumica sa kojom se čitalačka publika suočava pred sam kraj romana kada postavlja pitanje identiteta genijalne prijateljice. Iako se stiče utisak da se epitet „genijalna” pripisuje Lili, neposredno pred venčanje rejonske Džeki Kenedi $^{6}$, jedna rečenica koju izgovara buduća mlada odvlači našu pažnju u potpuno drugom smeru: ,[...] ti si moja genijalna prijateljica, moraš da postaneš bolja od svih, i od muškaraca i od žena" (Ferante 2011: 312).

Moglo bi se zaključiti da je funkcija prevoda u ciljnoj kulturi isticanje aktuelnosti centralnih tema koje ovaj roman tretira. Položaj žene, njena emancipacija u svetu u kojem pretežno vladaju maskulini principi, ali i razumevanje njenog najintimnijeg $j a$, relevantna su pitanja i danas u mnogim savremenim društvenim zajednicama. Sa druge strane, nespornu ulogu u recepciji ima $i$ vešto razrađena narativna struktura i autorkino znalačko otkrivanje najdubljih slojeva svojih likova iz kojih, kao iz palimpsesta, nastoji da izvuče i najmračnija osećanja. Budući da se kroz čitanje romana jasno uočava majčin uticaj

\footnotetext{
${ }^{5}$ Izdavačka kuća Booka profilisala se u objavljivanju savremene literature koja je dodatno popularizovana zahvaljujući promotivnim aktivnostima na društvenim mrežama.

${ }^{6}$ Ovim imenom Elena naziva Lilu kada se od odrpane obućareve kćeri transformiše u pravu divu rejona (,U najdubljoj dubini, bilo je to ono što sam zaista želela: da Lilu vratim bledoj Lili: konjski rep, skupljene oči grabljivice, odeća - krpe od dve pare. Ništa od važnosti, ponašanja kao da je rejonska Žaklina Kenedi” (Ferante 2011: 310).
} 
na uobličavanje identiteta protagonistkinje Elene, u nastavku rada pokušaćemo da otkrijemo na koji način odnos koji se između njih dve razvija, doprinosi recepciji ovog književnog dela.

\section{LIK ĆERKE I LIK MAJKE - PRIKAZ NJIHOVOG ODNOSA}

Premda $\mathrm{u}$ recepciji ovog romana važnu ulogu ima centralna tema prijateljstvo između dve žene - ne treba zanemariti značaj odnosa koji protagonistkinja razvija sa majkom. Autorka detaljno pristupa razotkrivanju veze koja nastaje između majke i ćerke, te se disfunkcionalnost $\mathrm{u}$ njihovom odnosu percipira kroz čitanje ne samo ovog već i ostalih delova napuljske tetralogije. $U$ analizi ovog odnosa treba imati na umu da ćerka nosi ulogu pripovedačice, te se događaji nižu i predstavljaju samo iz njene perspektive. Dakle, glas majke nemoguće je direktno čuti, već se njen lik tumači isključivo na osnovu predstava koje o njoj ima Elena. Kod nekih italijanskih kritičara zapaža se strog stav prema ovakvom pripovedanju, pa tako Donaruma navodi da naratorka „,ne može ni znati, ni razumeti sve o Lili” (Donnarumma 2016: 142), što bi se moglo zaključiti i kada je reč o predstavljanju lika majke. Međutim, ukoliko se osvrnemo na ostala dela Elene Ferante ${ }^{7}$, možemo primetiti da se te pripovedačke uloge smenjuju - u nekim romanima glas pripovedačice pripada majci, a u drugima ćerci - što upućuje na zaključak da je rasvetljivanje ovog odnosa jedan od glavnih zadataka koje autorka sebi postavlja.

Priroda veze između ćerke i majke igra važnu ulogu u ćerkinom društvenom životu i jedan je od odlučujućih faktora za njeno pozitivno psihološko funkcionisanje, te samopouzdanje (Onayli \& Erdur-Baker 2012: 327). U skladu sa tumačenjima koje iznosi Čodorov, Adalđiza Đorđo ističe da, iako se ćerka u procesu stvaranja svog identiteta povezuje sa majkom, ta veza biva obeležena konfliktnim željama za povezivanjem, ali i odvajanjem od majčinog tela. Ćerka odbacuje majku, pogotovo u starijem uzrastu, jer postaje svesna femininosti kao „negativno vrednovane rodne kategorije” (Chodorow u: Giorgio 2020: 21), što je moguće prevazići jednakom raspodelom roditeljskih uloga (ibid.). Ova teza nas ponovo dovodi do osnovnog uzroka problema sa kojim se Elena suočava patrijarhalne matrice kao osnovne paradigme zapadne kulture, čijih stega pokušava da se oslobodi glavna junakinja ovog romana.

7 L'amore molesto (Mučna ljubav) 1992, I giorni dell'abbandono (Dani napuštenosti) 2002, La figlia oscura (Mračna kći) 2006, La vita bugiarda degli adulti (Lažljivi život odraslih) 2019. 
Kroz čitanje romana uočava se autorkina namera da Elenu karakterno prikaže kao suprotnost najboljoj prijateljici ${ }^{8}$ navodeći raznolike situacije u kojima okolina različito percipira njihove karaktere. Elenu celo predgrađe doživljava kao pristojnu, poslušnu, dobronamernu i ljubaznu devojku. Uprkos opštem pozitivnom prikazu, možemo se složiti sa zapažanjem koje iznosi Pjaca kada navodi da čitateljska publika sa njom ne želi da se identifikuje (Piazza 2020: 54). U liku Elene prepoznaje se podvojenost u ženskim odnosima - sa majkom i Lilom (a kasnije i ćerkama) - u kojima ona ispituje i gradi sopstveni identitet (ibid.). Već u ovom prvom romanu opaža se Elenino osećanje zavisnosti od Lile, ali i ambijenta u kom se nalazi, kao i stalno traženje potvrde, odnosno priznanja za sopstvena dela (Donnarumma 2016: 142). Kroz takav narativ ona čitaocu otkriva svoje slabosti, strahove, stalni osećaj inferiornosti koji će je mučiti do zrelog doba. Upravo zbog tako otvorenog prikaza svog unutrašnjeg bića, Elena izaziva znatiželju kod čitalačke publike koja se možda ne poistovećuje u potpunosti sa njenim likom, ali na mahove prepoznaje njene nedoumice i emocije kao svoje lične.

Kako bismo jasnije sagledali lik protagonistkinje Elene, pokušaćemo da rasvetlimo njene predstave o drugosti. Kada je reč o slici drugog koja se izučava u okviru imagologije, najčešće se misli na predstavu stranca ili odnos književnog dela i kulture u kojoj ono nastaje (Milanović 2012: 89). Ipak, ova istraživanja, započeta u okvirima komparativne književnosti pedesetih godina 20. veka, u novije vreme proširuju pojam drugog i na oblast kulture, politike, ekonomskog ili geografskog statusa (ibid. 90). Mi ćemo se ovde zadržati na Eleninoj predstavi funkcionisanja društva i kulture iz koje potiče. Na početku drugog poglavlja (Detinjstvo - Priča o don Akileu), kroz opsežne opise i živopisne detalje, Elena uvodi čitalačku publiku u turobni ambijent prepun nasilja, kako u kući tako i na ulici. Upečatljiv je način na koji naratorka vidi žene u svom rejonu:

Žene su se međusobno borile žustrije od muškaraca, čupale su se za kosu, povređivale se. Nanositi bol bila je bolest. Kao devojčica, zamišljala sam vrlo male životinje, bezmalo nevidljive, kako noću dolaze u rejon, izlaze iz svojih baruština, iz neupotrebljivih železničkih vagona iza nasipa, iz nečistih trava nazvanih smrdljevak, iz žaba, guštera, muva, kamenja iz prašine i ulaze u vodu i hranu i vazduh, navodeći naše mame, bake da se naljute kao pobesnele kučke. Bile su zagriženije od muškaraca jer su muškarci bili neprekidno besni, ali bi se na kraju smirivali, dok su žene,

\footnotetext{
${ }^{8}$ Lila je buntovna i prkosna, obuzeta brojnim sopstvenim demonima.
} 
naizgled tihe, staložene, kad bi se naljutile, išle do krajnjih granica ludila i nisu se zaustavljale (Ferante 2016: 33-34).

U ovakvom prikazu naslućuje se naratorkin očaj i strah od tog kolektivnog atavizma koji pršti na sve strane, kontaminirajući pritom i nove generacije. Ovakvu predstavu neposredne okoline Elena ne uspeva da otkloni tokom odrastanja, ona ostaje duboko urezana u njoj čak i u poznim godinama kada piše svoju priču. Stoga bi i Elenino pripovedanje sa višedecenijskim otklonom moglo da se protumači, ne samo kao vrsta ispovesti, iz potrebe da sebi olakša, već i kao terapeutski pokušaj oslobađanja od negativnih emocija i stereotipnih slika. U delu su prisutni i drugi, brojni imagološki elementi, među kojima se izdvaja deo kada naratorka jezgrovito iznosi autodefiniciju mentaliteta i kulture kojoj pripada opisujući atmosferu tokom proslave Lilinog venčanja:

Mi smo bili plebs. Plebs je bilo ono otimanje hrane zajedno s vinom, ono svađanje ko je prvi poslužen i to bolje, onaj štrokavi pod po kojem su prolazili i opet prolazili kelneri, te sve prostije zdravice. Plebs je bila moja majka koja se napila, pa se sada naslonila na očevo rame, a on je bio ozbiljan, i smejala se razjapljenih usta na seksualne natuknice trgovca metalom. Svi su se smejali, a i Lila takođe [...] (Ferante 2016: 325-326).

Ovakvim opisima Elena nam ukazuje koliko za nju postaje nepodnošljiv teret takve drugosti. Osvestivši sliku tog sveta, sveta njene majke, sveta u koji i Lila samovoljno ulazi nakon venčanja, ona odlučuje da to neće biti njen svet.

Prikazana u poziciji objekta naracije, Elenina majka predstavlja tipičan primer majčinskog modela, ne samo u posleratnoj Italiji već i u mnogim drugim ratom razorenim zemljama Evrope. Pošto joj autorka, tj. pripovedačica, ne pominje ime, može se naslutiti da je njoj data samo uloga majke kao prirodne uloge koja joj pripada, dok su njeni drugi aspekti žene potpuno zanemareni. U nameri da analiziramo ovu majčinsku figuru neophodno je da se osvrnemo na činjenicu da su u 19. veku reči ,žena” i „majka” smatrane sinonimima. Tek nakon osnivanja ženskog pokreta krajem šezdesetih godina prošlog veka, žene nastoje da razdvoje ova dva identiteta (Snitou 2001: 12). Stoga je sasvim jasno da Elenina majka, odrasla u društvu koje „stvara polnu podelu psihičke organizacije i orijentacije" (Čodorov 2001: 35) između muškaraca i žena, predstavlja ženumajku koja ima zadatak da vaspita ćerku na isti način na koji je i sama odgojena. U figurativnom smislu, nju bismo mogli posmatrati kao taoca patrijarhalnog društva, ženu naizgled nesvesnu svog položaja, načina života, te nametnutih vrednosti koje ćutke prihvata. Polazeći od pretpostavke da su polovinom XX veka 
po sličnom obrascu živele i žene širom naše zemlje, elemente problematičnog odnosa koji se razvija između protagonistkinje i njene majke, ženski deo naše čitalačke publike mogao bi da prepozna na sopstvenom ili primeru najbližih žena iz svoje okoline. Tako ova priča izlazi iz granica malog, siromašnog napuljskog rejona, te sa lokalnog nivoa prelazi na globalni, navodeći nas da preispitamo svoje, ali i životne izbore naših majki i baka.

Sklona surovoj iskrenosti, bez trunke ulepšavanja, naratorka nas upoznaje sa svojom majkom na sledeći način:

Moja majka je bila problem, s njom stvari nikada nisu bile kako bi trebalo. Činilo mi se već tada, a imala sam nešto više od šest godina, da radi sve kako bi mi stavila do znanja da sam površna. Nisam joj bila simpatična, a ni ona meni nije bila simpatična. Odbijalo me je njeno telo, što je najverovatnije naslućivala. [...] nikad nije bilo jasno gde gleda njeno oko. Ni desna noga joj nije dobro radila [...]. Šepala je, i njen korak me je uznemiravao [...] (Ferante 2016: 41).

Kroz ceo roman, ona se iznova vraća isticanju majčinih fizičkih mana otkrivajući zbog toga stid, ali i golemi strah da će i sama postati takva. Kada promene na telu usled ulaska $\mathrm{u}$ adolescentski period postanu očigledne, Elena, očajna zbog svog novog izgleda, biva sve nesigurnija u sebe: „Nisam više znala ko sam. Počeh da sumnjam da ću se sve više menjati, sve dok ne izbije na videlo moja majka, hroma, zrikava, i tada me niko neće voleti” (Ferante 2016: 92). Pridajući veliki značaj jeziku kojim se služe likovi u romanu, pripovedačica im pripisuje različite društveno-kulturološke statuse - dijalekat ${ }^{9}$ je prirodni jezik, ali i jezik nasilja, dok je italijanski jezik obrazovanog sveta. U jednom od opisa majke Elena otkriva još jedan majčin nedostatak, njenu neobrazovanost:

[...] stidela sam se zbog razlike između skladne figure dostojanstveno obučene profesorke, njenog italijanskog koji je pomalo ličio na onaj iz Ilijade, i iskrivljene figure moje majke, starih cipela, kose bez sjaja, dijalekta što zavrće na italijanski bez gramatike (Ferante 2016: 88).

Premda se kroz ceo roman čita naratorkin izrazito negativan stav prema majci, tek na nekoliko mesta čitateljka odnosno čitalac upoznaje majčinu nežnu

\footnotetext{
9 Širom Italije u govoru se koriste mnogobrojni dijalekti, dok se standardnim jezikom smatra italijanski jezik čiji je položaj ozvaničen tek nakon ujedinjenja Italije 1861. godine. Iako pribegava upotrebi napuljskog dijalekta u vrlo retkim situacijama, najčešće vulgarnim doskočicama, naratorka jasno ukazuje na to da je on važno obeležje ambijenta u kojem živi.
} 
stranu. Te retke trenutke majčine skromno iskazane naklonosti naratorka nam otkriva prikazujući epizode o srebrnoj narukvici (Ferante 2016: 115), pripremama za letovanje na Iskiji (Ferante 2016: 205), te popravnom iz latinskog kada joj majka grubim tonom govori:

- Časove ne možemo da ti platimo, ali možeš da pokušaš sama da učiš i vidiš možeš li da položiš - Pogledah je nesigurno. Uvek je bila ista: bledunjava kosa, šetajuće oko, mesnati nos, krupno telo. Dodade: - Nigde ne piše da ne možeš da uspeš - (Ferante 2016: 101).

Majčina uloga u Elenininom razvoju je neosporna bez obzira na ćerkine pokušaje da se od nje distancira. Pozivajući se na De Rogatis i njeno tumačenje njihovog odnosa, Bobičić naglašava da taj odnos neretko biva ograničen patrijarhalnom dominacijom, ali da upravo majka određuje i definiše ćerku (Bobičić 2017: 5). Budući da protogonistkinja živi u vremenu u kojem je obrazovanje izbor samo nekolicine, pre svega muške populacije, savim je prirodno da majka ne razume ćerkinu želju da krene drugačijim putem od njenog. Stoga se može naslutiti da majka, frustirana sopstvenom nesposobnošću da vaspita ćerku onako kako priliči, Elenu doživljava kao lični neuspeh. Sa druge strane, Elena, usled nedostatka majčine podrške i stalnog osećaja nesigurnosti, smatra majku preprekom, te neprestano traži podstrek od drugih ženskih likova kojima veruje.

\section{ZAKLJUČAK}

$\mathrm{Na}$ osnovu analize koju smo sproveli mogli bismo da zaključimo da ovaj bildungsroman, usled stabilnih političko-ekonomskih odnosa sa zemljom iz koje dolazi izvorni tekst, geografske bliskosti, ali i opšte pozitivne slike o izvornoj kulturi, nailazi na povoljne okolnosti za prijem u Srbiji.

Kao najznačajniji faktor za recepciju ovog romana izdvaja se kulturološki kontekst u kom dolazi do transponovanja teksta. Ciljna kultura prepoznaje značaj tema koji roman tretira - socijalni položaj žene u patrijarhalnom društvu i nametanje određene kulturološke uloge ženi - te ga prihvata na svom putu ka rodno senzibilnom društvu. Izvesno je i da protagonistkinja Elena, kroz odrastanje $\mathrm{u}$ tradicionalnom ambijentu te stalnim pokušajima otklona od ideologije muške supremacije, ima važnu ulogu u recepciji romana kako kod kritike tako i kod čitalačke publike. Verujemo da je njen značaj upravo u toj tihoj, ali upornoj borbi za obrazovanjem, u kome vidi izlaz iz siromaštva i primitivizma. Ključna figura za dublje razumevanje Eleninog lika jeste njena majka, koja svojim (ne)delovanjem postaje saučesnik u održanju patrijarhata. Kroz analizu njihovog odnosa uočavamo 
da se bivstvovanje mlade Elene pozicionira u okviru struktura koje se međusobno neprestano suprotstavljaju, kroz njene izmešane emocije, odnosno želju da se otrgne od nametnute potčinjenosti patrijarhalnom obrascu i potrebu da naiđe na odobravanje za svoje izbore. Elena prema majci gaji osećaj prezira, te se stiče utisak da u lik majke projektuje sve što žena predstavlja u tom zatvorenom ambijentu. Majka postaje simbol tipične žene iz rejona, prema kojoj Elena izražava animozitet. Stoga se može zaključiti da je Elenin strah od fizičke transformacije u sopstvenu majku moguće tumačiti kao strah od ukalupljivanja u turobni život rejona.

Smatramo da autorka, ovako ogoljenim prikazom kompleksnog odnosa ćerke i majke, podstiče čitalačku publiku da i sama preispita svoje odnose sa roditeljskim figurama, koji su u našoj kulturi $\mathrm{i}$ danas često obojeni emancipatorskim i antiemancipatorskim stavovima.

\section{LITERATURA}

Bazdulj, Muharem. 2015, Septembar 3. „Videti Napulj i pisati”. Vreme. https://www.vreme.com/cms/view.php?id=1324800 (10.06.2021).

Bobičić, Nađa. 2017. „Tema majčinstva u ranim romanima Elene Ferante”. Genero 21: 1-18. http://generojournal.org/genero-21-2017-sr.html (12.04.2021).

Čodorov, Nensi. 2001. „Reprodukcija materinske uloge”. O rađanju, prir. Biljana Dojčinović. Beograd: Ažin, 30-35.

Donnarumma, Raffaele. 2016. "Il melodramma, l'antimelodramma, la Storia: sull'Amica geniale di Elena Ferrante". Allegoria 73: 138-147.

Ferante, Elena. 2016. Moja genijalna prijateljica (2. izd.). Beograd: Booka.

Ferrara, Enrica, Maria. 2020. "Tiziana De Rogatis Elena Ferrante's key words". Annali d'italianistica, vol. 38: 559-561.

Giorgio, Adalgisa. 2002. Writing the Mothers and Daughters: Renegotiating the Mother in Western European Narratives by Women. Oxford: Berghahn.

Krtinić, Marija. 2020, Septembar 1. „Zašto volimo da čitamo dela Elene Ferante?” Danas. https://www.danas.rs/kultura/zasto-volimo-da-citamo-dela-eleneferante/ (19.05.2021).

Lalatović, Jelena. 2017. „Napuljska tetralogija pod lupom feminističke naratologije". Genero 21: 43-59. http://generojournal.org/genero-212017-sr.html (13.04.2021).

Milanović, Željko. 2012. „Granice imagologije“. Pravo i društvo 3-4: 89-98. 
Milinkov, Smiljana. 2014. „Medijska prezentacija žena pedesetih godina prošlog veka u Jugoslaviji: retradicionalizacija društva vs. Emancipacije na primeru Autonomne pokrajine Vojvodine". Narodna umjetnost, vol. 51, br.2: 173-190. https://www.researchgate.net/publication/290503633_ Medijska_prezentacija_zena_pedesetih_godina_proslog_veka_u_ Jugoslaviji_retradicionalizacija_drustva_vs_emancipacije_na_primeru_ Autonomne_pokrajine_Vojvodine (02.06.2021).

Onalyi, Selin \& Erdur-Baker, Ozgur. 2012. "Mother-daughter relationship and daughter self-esteem". Elselvier, vol. 84: 327-331. https://www.sciencedirect.com/science/article/pii/S1877042813016273 (18.05.2021).

O'Rourke, Meghan. 2014, October 31. "Elena Ferrante: the global literary sensation nobody knows". The Guardian. https://www.theguardian.com/ books/2014/oct/31/elena-ferrante-literary-sensation-nobody-knows (29.04.2021).

Piazza, Isotta. 2020. "La perfezione della trama, le falle del raconto. Postille a L'amica geniale". MediAzioni 28: 48-65. http://mediazioni.sitlec.unibo.it (22.05.2021).

Ricci, Luca. 2015, Marzo 19. "Il fenomeno Elena Ferrante visto dai critici”. Il Messaggero. https://www.ilmessaggero.it/spettacoli/libri/elena_ferrante_ opinione_critici-930631.html (16.10.2021).

Savković, Mladen. 2019, Januar 5. „Svi su ludi za Elenom Ferante”. Ključaonica. https://kljucaonica.com/2019/01/05/svi-su-ludi-za-elenom-ferante/ (12.04.2021).

Schwartz, Cecilia. 2020. "Ferrante Feud: The Italian Reception of the Neapolitan Novels before and after their International Success". The Italianist, vol.40, no.1: $122-142$.

Scaffai, Niccolò. 2018. "Leggere l'Italia. Traduzione e ricezione della letteratura italiana contemporanea all'estero". À l'italienne:Narrazioni dell'italianità dagli anni Ottanta a oggi: 41-57.

Sirković, Nina. 2011. „Ženski glasovi u romanu: razvoj junakinje Bildungsromana". Knjiženstvo-časopis za studije književnosti, roda $i$ kulture. http://www.knjizenstvo.rs/sr/casopisi/2011/zenska-knjizevnost-ikultura/zenski-glasovi-u-romanu-razvoj-junakinjebildungsromana\#gsc.tab=0 (11.05.2021).

Simon, Sherry. 2005. Gender in translation-Cultural Identity and the Politics of Transmission. London\&New York: Routledge. 
Snitou, En. 2001. „Feminističke analize materinstva”. O rađanju, prir. Biljana Dojčinović. Beograd: Ažin.11-17.

Stojnić, Mila. 1980. O prevođenju književnog teksta. Sarajevo: Svjetlost.

Šljukić, Dara. 2017. „Kvir čitanje romana Elene Ferante Moja genijalna prijateljica". Genero 21: 61-84. http://generojournal.org/genero-21-2017sr.html (12.04.2021).

Veselinović, Sonja. 2018. Recepcija, kanon, ciljna kultura. Slika modernog angloameričkog pesništva u savremenoj srpskoj književnosti. Novi Sad: Akademska knjiga.

Jelena V. Badovinac

RECEPTION OF ELENA FERRANTE'S NOVEL MY GENIUS FRIEND THROUGH THE PRISM OF THE RELATIONSHIP BETWEEN THE FEMALE PROTAGONIST AND HER MOTHER

\section{Summary}

In this paper, we highlight the most important aspects that affect the reception of Elena Ferrante's novel My genius friend in our country. We also examine in detail the cultural context in the transfer of the novel into the Serbian language and determine the function that its translation has in the target culture. Bearing in mind their relevance in the evaluation and reception of a literary work, we analyse the viewpoints expressed by the domestic literary critics regarding the first novel of the Neapolitan tetralogy. Since the aim of the paper is to discover the role that the female protagonist and her mother have in the reception, we pay special attention to the complex relationship that develops between them. In order to determine the impact of their relationship on the reception of this novel, we analyze the character of Elena, determined on her path to emancipation, and the character of the mother who does not resist the discipline of patriarchy, but accepts it as a necessity. Focusing on the dynamic relationship marked by antagonism between two generations of women, we seek to point out that our readers perceive it as a close personal experience.

Key words: Elena Ferrante, My genius friend, reception, readership, mother-daughter relationship, patriarchal culture, emancipation 